\title{
Backbone and Side-Chain Cleavages in Electron Detachment Dissociation (EDD)
}

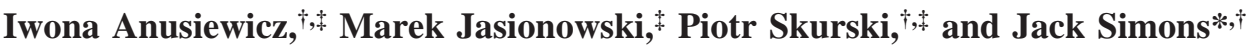 \\ Department of Chemistry and Henry Eyring Center for Theoretical Chemistry, University of Utah, Salt Lake \\ City, Utah 84112, and Department of Chemistry, University of Gdansk, Sobieskiego 18, 80-952 Gdansk, Poland
}

Received: September 5, 2005; In Final Form: October 20, 2005

\begin{abstract}
Ab-initio electronic structure methods are used to explore potential energy profiles pertinent to the fragmentations of gas-phase radicals thought to be formed in the new negative-ion mode EDD mass spectroscopic studies of peptides. Barriers to fragmentation as well as the associated overall energy differences are computed for the observed $\mathrm{C}_{\alpha}-\mathrm{C}$ backbone bond cleavage as well as for side-chain loss for a variety of side chains (valine, arginine, glutamic acid, and tyrosine). It is found that $\mathrm{C}_{\alpha}-\mathrm{C}$ bond cleavage is favored over side-chain loss, although loss of a tyrosine side chain may compete with $\mathrm{C}_{\alpha}-\mathrm{C}$ cleavage because the tyrosine radical formed can delocalize its unpaired electron over its aromatic ring. In addition, it is found that fragmentation of the nitrogen-centered radicals formed in EDD results in cleavage to produce so-called a $\bullet / x$ fragments rather than $\mathrm{a} / \mathrm{x} \bullet$ fragments both because producing the former involves a significantly smaller barrier and is nearly thermoneutral, while cleavage to yield $\mathrm{a} / \mathrm{x} \bullet$ is significantly endothermic.
\end{abstract}

\section{Introduction}

Electron-capture dissociation (ECD) mass spectrometry has proven $^{1}$ to be a very useful tool for probing peptide and protein primary structures primarily because of the strong propensity for $\mathrm{N}-\mathrm{C}_{\alpha}$ and $\mathrm{S}-\mathrm{S}$ bond cleavages to occur throughout much of the backbone. These experiments involve attaching lowenergy electrons to multiply positively charged samples. After electron attachment, for example to a protonated amine site, and transfer of an $\mathrm{H}$ atom to a carbonyl oxygen atom, it is believed that a carbon-centered radical (species III in Scheme 1 ) is formed. Subsequently, $\mathrm{N}-\mathrm{C}_{\alpha}$ bond cleavage occurs to form the characteristic $\mathrm{c}$ and $\mathrm{z} \bullet$ fragments as depicted in Scheme 1. The formation of the carbonyl carbon-centered radical plays a crucial role in inducing $\mathrm{N}-\mathrm{C}_{\alpha}$ bond cleavage because fragmentation of this radical along the pathway shown in Scheme 1 allows the nitrogen atom to subsequently form a $\mathrm{C}=\mathrm{N}$ $\pi$-bond ${ }^{2}$, thus stabilizing the products and lowering the barrier to $\mathrm{N}-\mathrm{C}_{\alpha}$ cleavage.

More recently, ${ }^{3}$ a new method for inducing backbone fragmentation, termed electron-detachment dissociation (EDD) mass spectrometry, has shown substantial promise as a means of generating $\mathrm{C}_{\alpha}-\mathrm{C}$ bond cleavages. This experiment is carried out in negative-ion mode and involves using electrons with kinetic energies above $10 \mathrm{eV}$ to detach electrons from the negative sites in the parent peptide or protein ion to convert the negative sites to radical centers. The locations of the negative charges in such samples include ${ }^{3 a}$ amide nitrogen atoms along the backbone (as well, of course, as $\mathrm{C}-$ terminus and sidechain carboxylate groups). When an electron is ejected from an amide nitrogen anion, nitrogen-centered radicals such as those shown in Scheme 2 are formed.

Upon forming such a nitrogen-centered radical, two $\mathrm{C}_{\alpha}-\mathrm{C}$ bond cleavage paths might be expected to occur. The path shown

* Corresponding author. Office: 801-581-8023. Fax: 801-581-8433. E-mail: simons@chem.utah.edu.

$\dagger$ University of Utah.

University of Gdans.
SCHEME 1

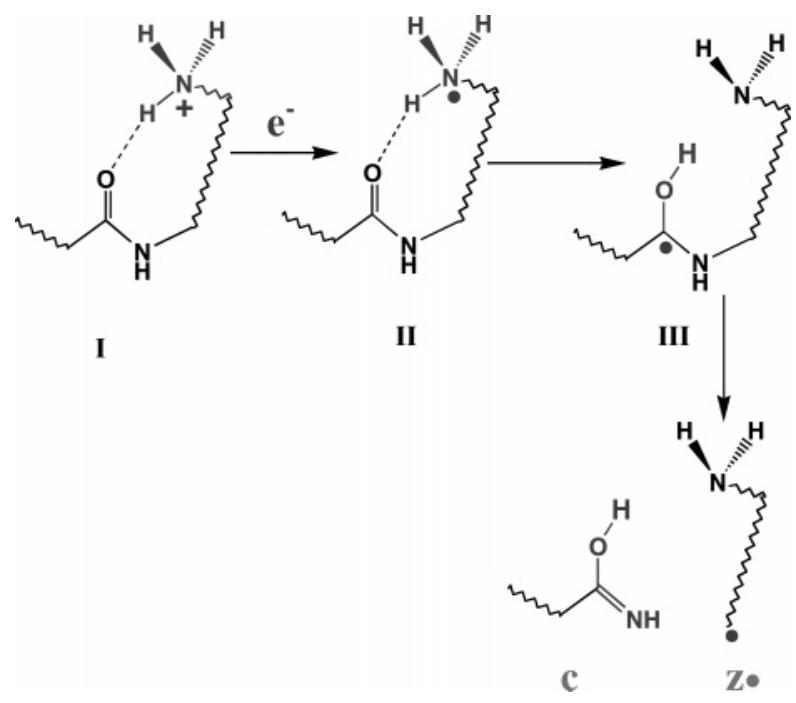

SCHEME 2

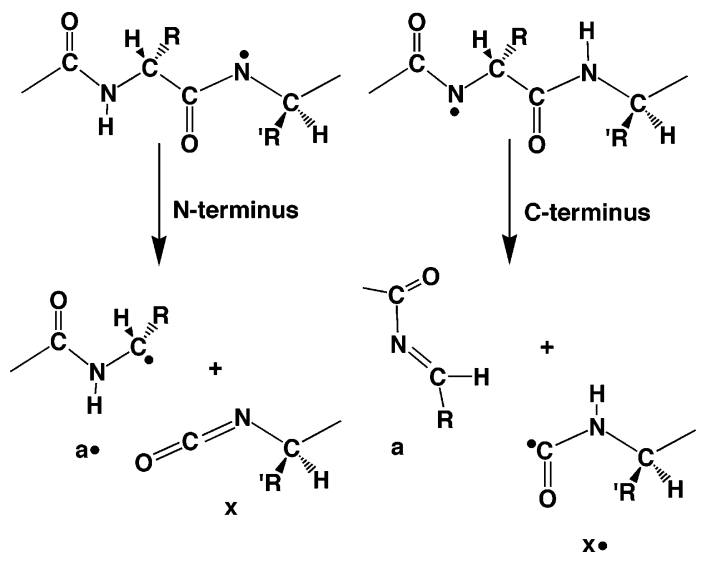

on the right in Scheme 2 involves cleavage of a $\mathrm{C}_{\alpha}-\mathrm{C}$ bond in which the $\mathrm{C}_{\alpha}$ carbon atom is adjacent to the nitrogen radical, 
while that shown on the left involves cleavage in which the $\mathrm{C}_{\alpha}$ carbon atom is adjacent to an amide $-\mathrm{NH}-$ group rather than the nitrogen radical. EDD experiments observe only the fragments denoted $\mathrm{a} \bullet \mathrm{x}$ that are characteristic of the left pathway and not the $\mathrm{a} / \mathrm{x} \bullet$ fragments belonging to the right path, and it is a part of the present study to further investigate why this is the case.

In the present work, we examine the energetics of the reaction pathways for $\mathrm{C}_{\alpha}-\mathrm{C}$ bond cleavage shown in Scheme 2, as well as for side-chain loss (i.e., loss of $\mathrm{R}$ rather than $\mathrm{C}_{\alpha}-\mathrm{C}$ cleavage) for the same kind of nitrogen-centered radicals as shown in Scheme 2. To calibrate our findings by comparing them with results obtained earlier by other workers, we also consider the energy profiles for $\mathrm{N}-\mathrm{C}_{\alpha}$ bond cleavage appearing in Scheme 1 and for side-chain loss from the same carbon-centered radical as appears in Scheme 1.

\section{Methods}

To allow us to examine backbone and side-chain bond cleavages arising from both carbon-centered and nitrogencentered radical species such as those appearing in Schemes 1 and 2, we chose the parent compound shown below as the starting point for all of our ab-initio calculations.<smiles>[2H][C@@H](NC(C)=O)C(=O)NC</smiles>

The group labeled $\mathrm{R}$ represents the side chain of one of the amino acids. In this project, we chose

(a) $\mathrm{R}=-\mathrm{CH}-\left(\mathrm{CH}_{3}\right)_{2}$, a valine side chain with no polar groups and with little, if any, delocalization of the radical center formed when the side chain is detached;

(b) $\mathrm{R}=-\mathrm{CH}_{2}-\mathrm{CH}_{2}-\mathrm{CH}_{2}-\mathrm{NH}-\mathrm{C}(=\mathrm{N})-\mathrm{NH}_{2}$, an arginine side chain containing the guanidinium unit and with hydrogenbonding capability but little delocalization of the radical center;

(c) $\mathrm{R}=-\mathrm{CH}_{2}-\mathrm{CH}_{2}-\mathrm{COOH}$, a glutamic acid side chain containing the carboxylic acid unit and with hydrogen-bonding capability but little delocalization of the radical center; and

(d) $\mathrm{R}=-\mathrm{CH}_{2}-\left(\mathrm{C}_{6} \mathrm{H}_{4}\right)-\mathrm{OH}$, a tyrosine side chain containing an $\mathrm{OH}$ group that can hydrogen bond and an aromatic ring adjacent to the $\cdot \mathrm{CH}_{2}-\left(\mathrm{C}_{6} \mathrm{H}_{4}\right)-\mathrm{OH}$ radical center that can delocalize (and thus stabilize) the radical formed when the side chain is released.

We used this collection because we wanted to explore how the energy profiles (i.e., barriers and thermochemistry) we observed depend on the polarities, hydrogen-bonding abilities, and delocalizing characters of the side chains.

The equilibrium geometries of all species have been optimized at the Hartree-Fock or B3LYP4 level of theory using 6-311+G* basis sets. ${ }^{5,6}$ We also calculated all vibrational frequencies to make sure the structures thus found were indeed minima on the energy surface or transition states connecting reactants to products. To generate the energy profiles for fragmentation processes, we performed second-order Møller-Plesset (MP2) and $\mathrm{QCISD}^{7}$ calculations with all geometrical degrees of freedom frozen at the SCF (optimized geometries) values. All of our calculations were carried out using the Gaussian 03 suite $^{8}$ of codes.

\section{Results and Discussion}

A. EDD Nitrogen Radical Initiated $\mathbf{C}_{\alpha}-\mathrm{C}$ Cleavages. In this series of calculations, we begin with a species appropriate

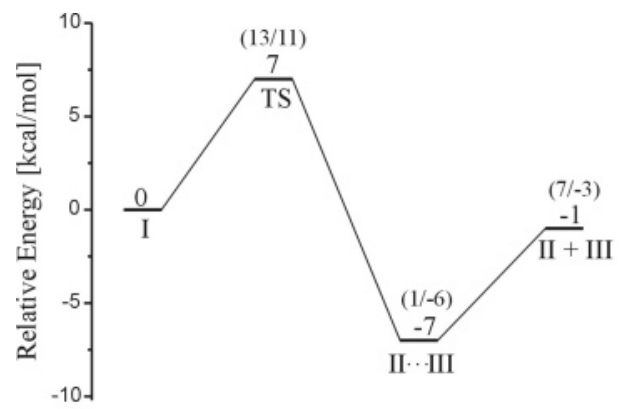

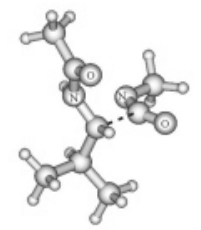

$\mathrm{TS}(\mathrm{I} \rightarrow \mathrm{II} \cdot \mathrm{III})$

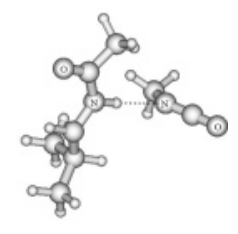

II $\cdots$ III
Figure 1. Energy profile for $\mathrm{C}-\mathrm{C}_{\alpha}$ bond cleavage from species I with the side chain of valine. Transition state (left) and product complex (right) structures are also shown.

\section{SCHEME 3}

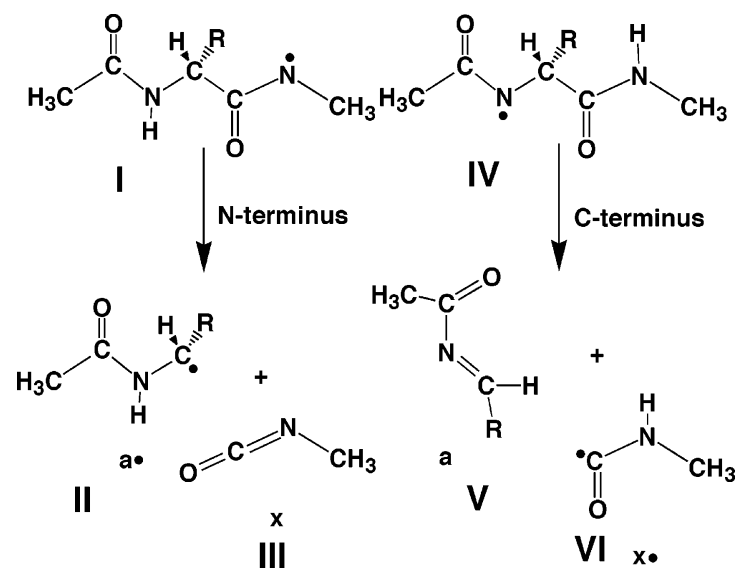

to the EDD experiments in which the radical center occurs at a backbone amide nitrogen atom and with the valine side chain. The two radicals we used are labeled I and IV in Scheme 3. In Figure 1 we show the energy profile associated with fragmentation to produce the $\mathrm{a} \cdot \mathrm{x}$ fragments, and in Figure 2 we show the corresponding energy profile for the reaction of Scheme 3 that generates the $\mathrm{a} / \mathrm{x} \bullet$ fragments. In both figures, the energy data shown in the larger labels correspond to QCISD-level energies obtained at SCF-optimized geometries. The energy data shown in parentheses are PMP2-level energies at SCF-optimized geometries (left) and B3LYP-level energies at B3LYP-optimized geometries (right). Because the SCF and B3LYP geometries are not very different, we believe that the QCISD data should be the most reliable in these cases. We chose to show such a variety of energies to give the reader a feel for the uncertainties that can be expected. For each cleavage path, we show the energies of the reactant radical (at zero energy), the transition state that must be overcome to effect cleavage, the association complex formed upon cleavage, and the separated fragments.

The most important observations to be made from Figures 1 and 2 are that

(a) cleavage to produce the $\mathrm{a} \bullet / \mathrm{x}$ fragments must overcome a significantly smaller barrier than for cleavage to yield $\mathrm{a} / \mathrm{x} \bullet$, and

(b) cleavage to produce the $\mathrm{a} \bullet / \mathrm{x}$ fragments is nearly thermoneutral, while cleavage to yield $\mathrm{a} / \mathrm{x} \bullet$ is significantly endothermic. 


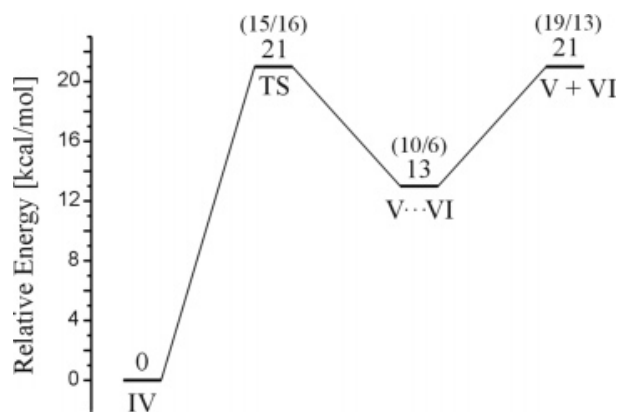

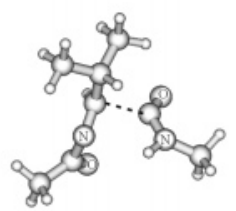

$\mathrm{TS}(\mathrm{IV} \rightarrow \mathrm{V} \cdots \mathrm{VI})$

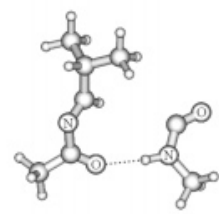

V...VI
Figure 2. Energy profile for $\mathrm{C}-\mathrm{C}_{\alpha}$ bond cleavage from species IV with the side chain of valine. Transition state (left) and product complex (right) structures are also shown.

\section{SCHEME 4}

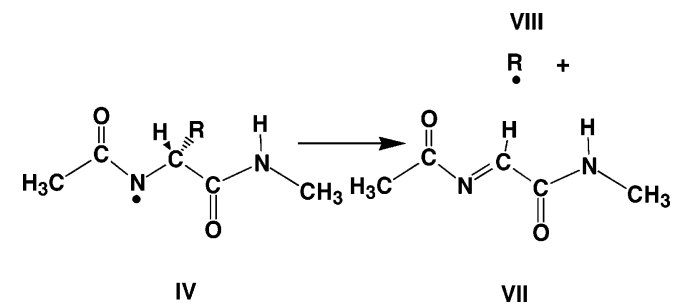

These findings are in line with the observation of $a \bullet / x$ products but not $\mathrm{a} / \mathrm{x} \bullet$ products in EDD experiments. It should be noted that the authors of ref $3 \mathrm{a}$ showed, through ab-initio calculations, that $\mathrm{a} \bullet \mathrm{x}$ products are energetically more stable than the corresponding $\mathrm{a} / \mathrm{x} \bullet$ products. However, these workers did not identify the transition states connecting the nitrogen-based radicals and the $\mathrm{a} \bullet / \mathrm{x}$ and $\mathrm{a} / \mathrm{x} \bullet$ products as we have done here, so they did not know whether kinetic considerations would also explain the preference for forming $\mathrm{a} \bullet / \mathrm{x}$ products.

B. EDD Nitrogen-Radical-Initiated Side-Chain Loss. We also considered the energy profiles governing the relative rates at which EDD experiments might be expected to realize sidechain loss in competition with the $\mathrm{C}-\mathrm{C}_{\alpha}$ cleavage of species I treated in section IIIA. In this series of calculations, we again begin with a species appropriate to the EDD experiments in which the radical center occurs at a backbone amide nitrogen atom. In particular, we use the radical labeled IV in Scheme 4.

Fragmentation to form the side-chain radical R• (labeled VIII) and species VII was examined for $\mathrm{R}$ being the side chain of valine, arginine, glutamic acid, and tyrosine. The corresponding reaction energy profiles we obtained are described in Figures 3-6. The energy data shown in larger print correspond to B3LYP-level energies at B3LYP-optimized geometries, while those shown in parentheses are PMP2-level energies obtained at SCF-optimized geometries. It is important to point out that, in the valine side-chain case, we experienced substantial spin contamination, so it is likely that the energy profile obtained for this case is not as reliable as in the other cases.

These data suggest that side-chain loss in EDD experiments that begin with a nitrogen-centered radical such as shown above are highly unlikely to occur at rates competitive with the $\mathrm{C}-\mathrm{C}_{\alpha}$ bond cleavage leading to $\mathrm{a} \bullet \mathrm{x}$ fragments. Only for the tyrosine
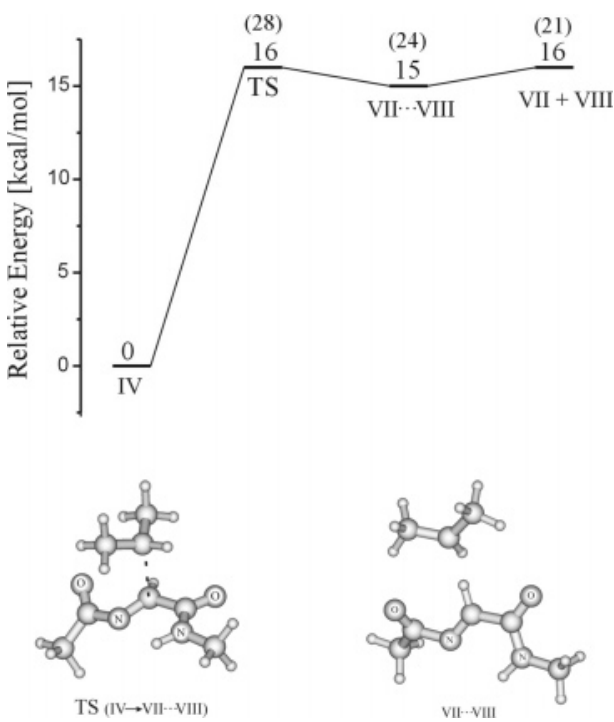

Figure 3. Energy profile for side-chain loss from species IV with the side chain of valine. Transition state (left) and product complex (right) structures are also shown.

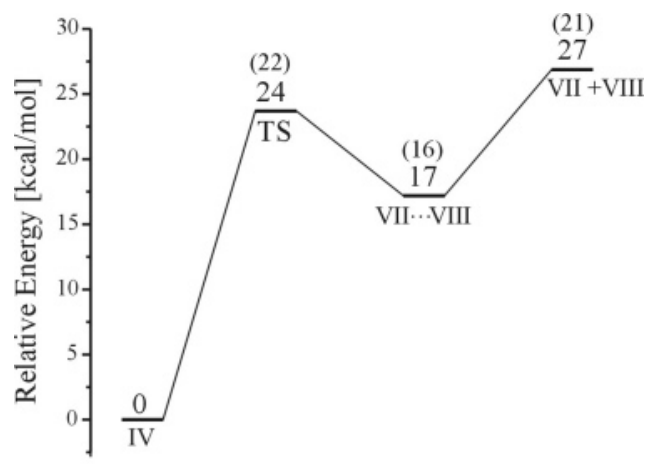

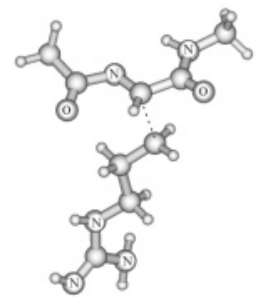

TS $($ IV $\rightarrow \mathrm{VII} \cdots \mathrm{VIII})$

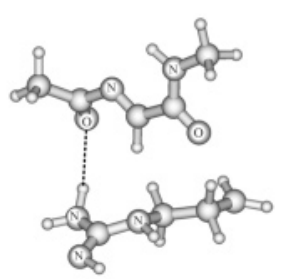

VII $\cdots$ VIII
Figure 4. Energy profile for side-chain loss from species IV with the side chain of arginine. Transition state (left) and product complex (right) structures are also shown.

side chain, ${ }^{9}$ which stabilizes the radical formed upon bond cleavage by delocalizing it over the phenyl ring, might sidechain loss be expected but still at rates significantly less than that of $\mathrm{a} \bullet / \mathrm{x}$ fragment formation. Moreover, for the tyrosine side chain, the data suggest that, if side-chain cleavage were to occur, the result would be an association complex that would require a substantial (ca. $7-8 \mathrm{kcal} \mathrm{mol}^{-1}$ ) additional energy input to undergo fragmentation. These observations about the relative rates of $\mathrm{C}_{\alpha}-\mathrm{C}$ and side-chain cleavages suggest that EDD fragmentation can be assumed to be dominated by $\mathrm{C}_{\alpha}-\mathrm{C}$ bond cleavage except when a very electron-delocalizing side chain such as tyrosine is proximal to the nitrogen radical center.

C. Carbon-Radical-Initiated $\mathbf{N}-\mathbf{C}_{\alpha}$ Cleavage. Although the focus of this work has been on considering the energy profiles associated with backbone and side-chain cleavages associated with nitrogen radicals characteristic of EDD experiments, we 

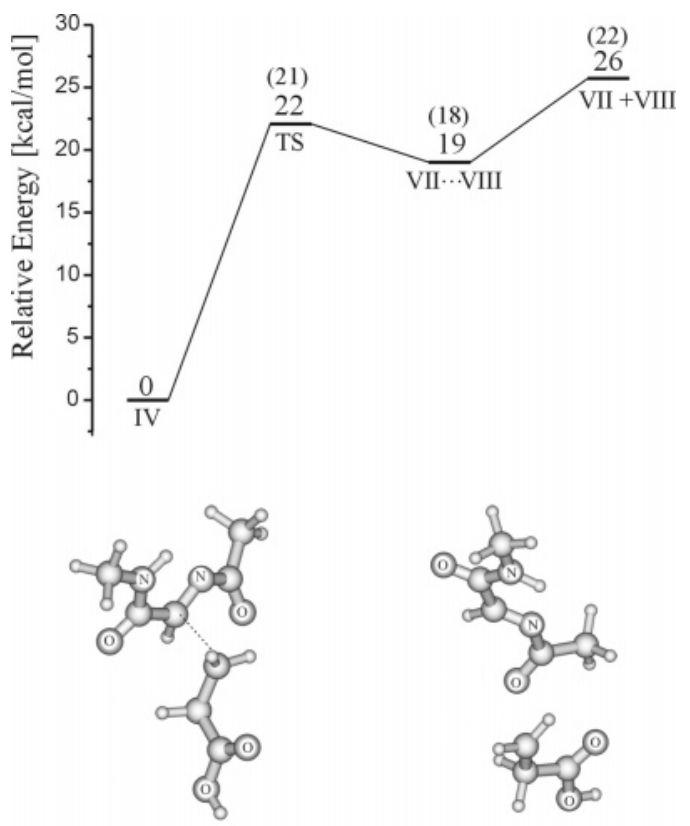

TS $(\mathrm{IV} \rightarrow \mathrm{VII} \cdots \mathrm{VIII})$

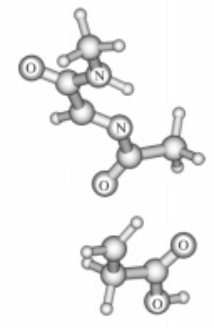

VII-V.VIII

Figure 5. Energy profile for side-chain loss from species IV with the side chain of glutamic acid. Transition state (left) and product complex (right) structures are also shown.

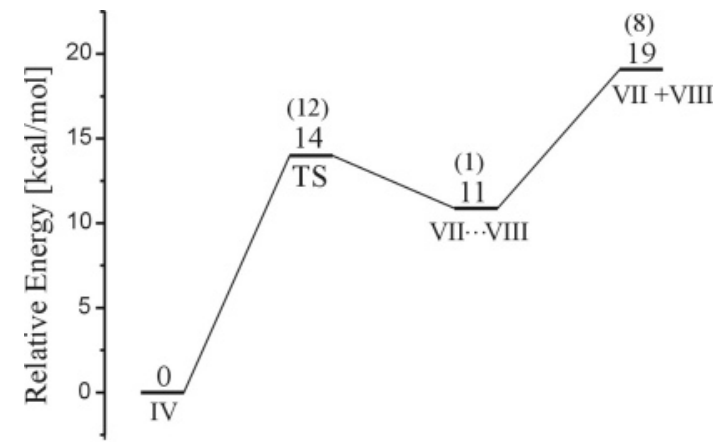

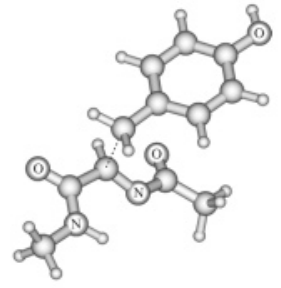

TS $($ IV $\rightarrow$ VII $\cdots$ VIII)

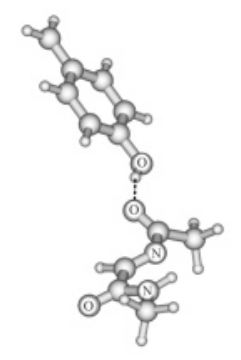

VII- VIII
Figure 6. Energy profile for side-chain loss from species IV with the side chain of tyrosine. Transition state (left) and product complex (right) structures are also shown.

decided to also consider $\mathrm{N}-\mathrm{C}_{\alpha}$ and side-chain cleavages for carbon-centered radicals characteristic of ECD experiments ${ }^{1}$. The former of these pathways has been studied before using ab-initio methods, and an outstanding overview as of 2004 is given by the Turecek group in ref $1 \mathrm{j}$. However, we believe considering both $\mathrm{N}-\mathrm{C}_{\alpha}$ and side-chain cleavages here offers the reader a comparison of the energy profiles operative in both EDD and ECD experiments, realizing, of course, that these experiments are performed on entirely different parent ions.

In this series of calculations, we again begin with a species appropriate to the ECD experiments in which the radical center occurs at a carbonyl carbon atom. In particular, we use the radical labeled IX in Scheme 5.

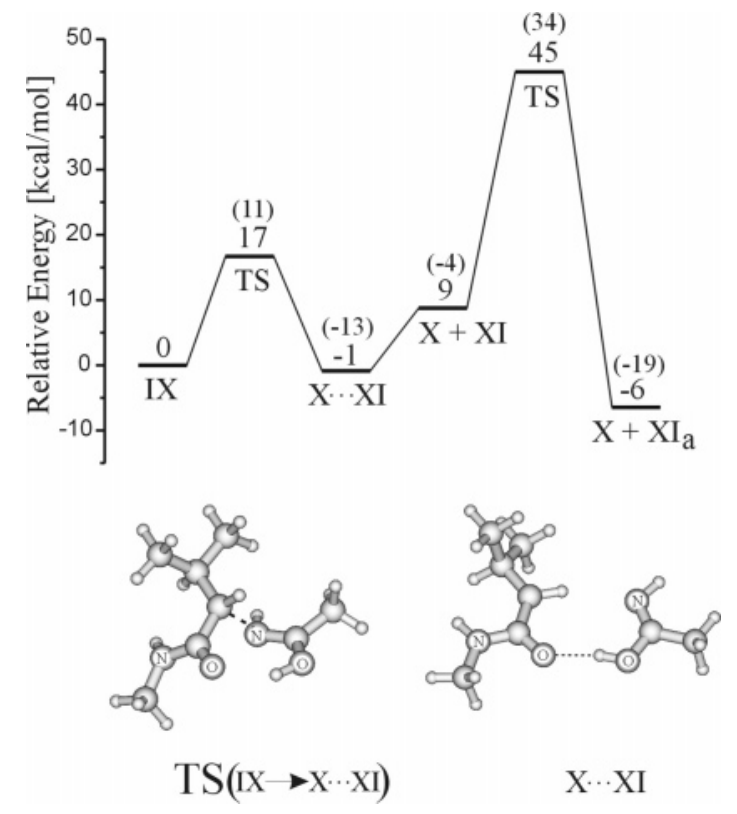

Figure 7. Energy profile for $\mathrm{N}-\mathrm{C}_{\alpha}$ bond cleavage in species IX with the side chain of valine. Transition state (left) and product complex (right) structures are also shown.

\section{SCHEME 5}

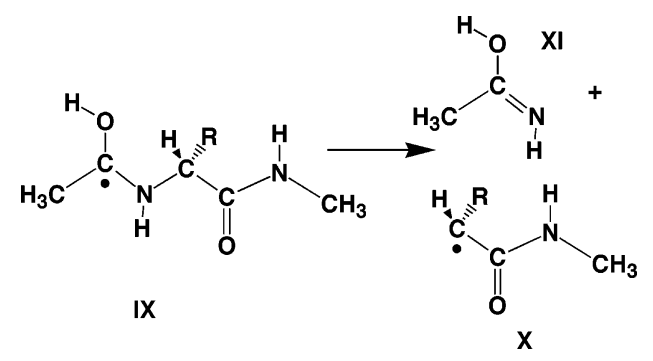

SCHEME 6

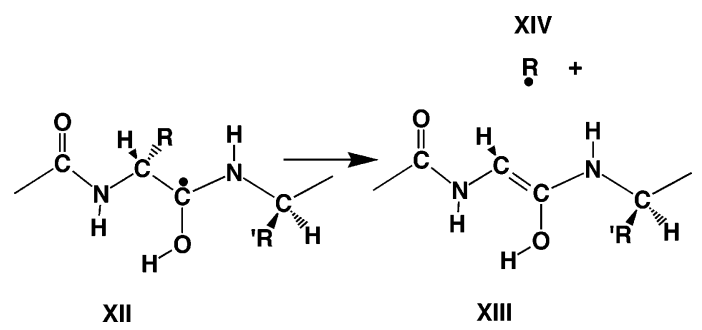

Fragmentation of the $\mathrm{N}-\mathrm{C}_{\alpha}$ bond to form the radical $\mathrm{X}$ and the imine XI was examined for $\mathrm{R}$ being the side chain of valine, and the reaction energy profile we obtained is described in Figure 7. The data shown in the larger print correspond to PMP2-level energies computed at SCF-optimized geometries, while those shown in parentheses are B3LYP-level energies at SCF-optimized geometries.

As in earlier figures, the energies of the parent radical (IX), the transition state (TS), and the complex (X‥XI) formed upon bond cleavage are shown, as is the energy of the separated fragment products $(\mathrm{X}+\mathrm{XI})$. However, in Figure 7 we also show the energy of the transition state (TS) connecting the $\mathrm{Me}-$ $(\mathrm{C}-\mathrm{OH})=\mathrm{NH}$ species $(\mathrm{XI})$ and the $\mathrm{Me}-(\mathrm{C}=\mathrm{O})-\mathrm{NH}_{2}$ species (labeled $\mathrm{XI}_{\mathrm{a}}$ ). We note that isomerization of XI to $\mathrm{XI}_{\mathrm{a}}$, in the gas phase as is appropriate to ECD experiments, although exothermic, must overcome a substantial barrier. This suggests that the products of $\mathrm{N}-\mathrm{C}_{\alpha}$ bond cleavage could remain in the $\mathrm{Me}-(\mathrm{C}-\mathrm{OH})=\mathrm{NH}$ stage under ECD conditions. 


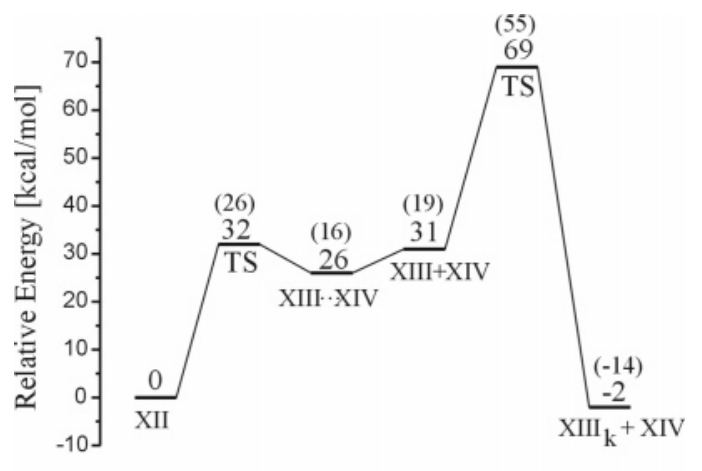

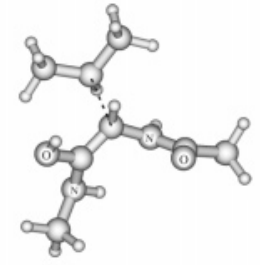

TS $(\mathrm{XII} \rightarrow \mathrm{XIII} \cdots \mathrm{xIV})$

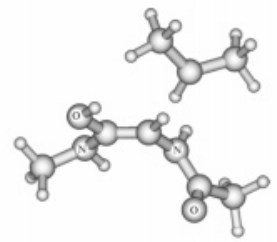

$\mathrm{XIII} \cdot \mathrm{XIV}$
Figure 8. Energy profile for side-chain loss from species XII with the side chain of valine. Transition state (left) and product complex (right) structures are also shown.
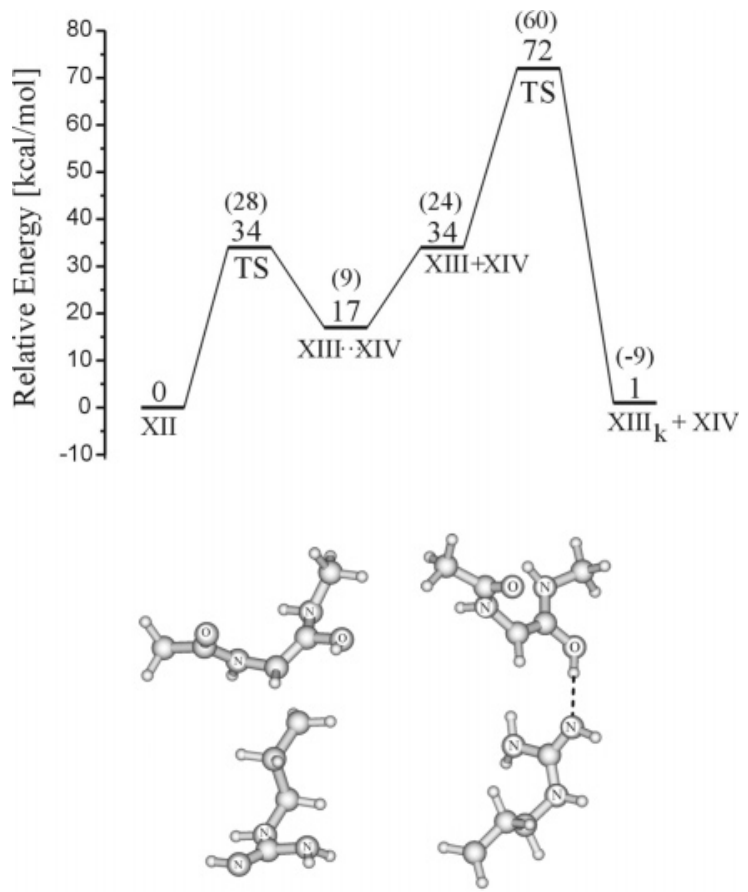

TS $(\mathrm{XII} \rightarrow \mathrm{XIII} \cdots \mathrm{xIV})$

$\mathrm{XIII} \cdot \mathrm{XIV}$

Figure 9. Energy profile for side-chain loss from species XII with the side chain of arginine. Transition state (left) and product complex (right) structures are also shown.

D. Carbon-Radical-Initiated Side-Chain Loss. In this series of calculations, we again begin with a species appropriate to the ECD experiments in which the radical center occurs at a carbonyl carbon atom. In particular, we use the radical labeled XII in Scheme 6.

Fragmentation to form the side-chain radical (XIV) R• and species XIII was examined for $\mathrm{R}$ being the side chain of valine, arginine, glutamic acid, and tyrosine. The reaction energy profiles we obtained are described in Figures 8-11 where the data presented in larger font and those in parentheses are as specified earlier for Figures 3-6. We note that, for the valine side chain, we did not experience the substantial spin contami-

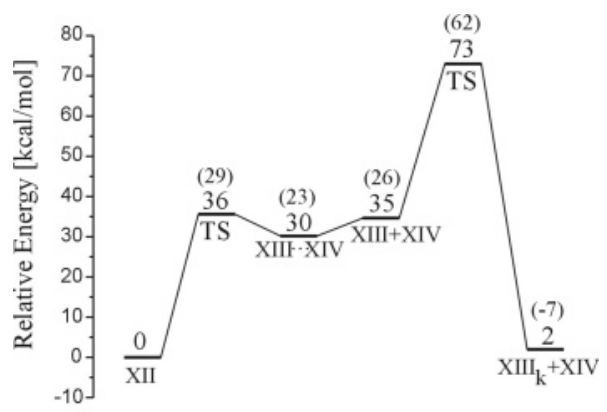

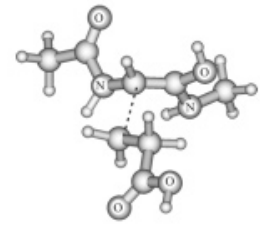

TS (XII $\rightarrow$ XIII $\cdots$ xIV)

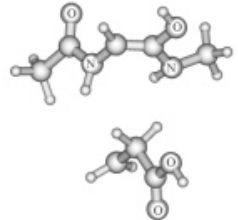

XIII"XIV
Figure 10. Energy profile for side-chain loss from species XII with the side chain of glutamic acid. Transition state (left) and product complex (right) structures are also shown.
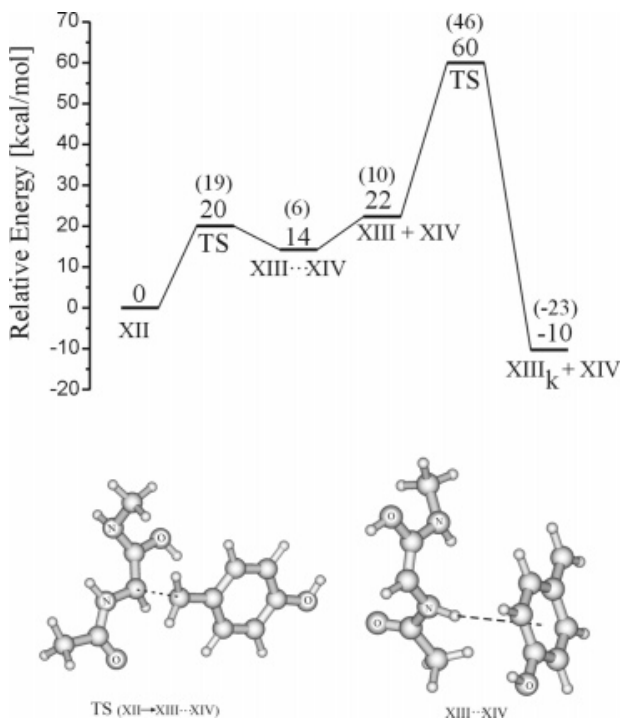

Figure 11. Energy profile for side-chain loss from species XII with the side chain of tyrosine. Transition state (left) and product complex (right) structures are also shown.

nation that plagued us in the data shown in Figure 3. So, in the present case, we believe there is every reason to expect the valine data to be as reliable as for the other side chains.

Again, the figures show the starting radical (XII), the transition state (TS), and the complex formed upon side-chain loss (XIII $\cdots$ XIV), as well as the separated fragments (XIII + $\mathrm{XIV})$. In addition, we show on the right, the transition state (TS) connecting the $-(\mathrm{HC})=\mathrm{C}(\mathrm{OH})-$ isomer of species XIII and the keto isomer $-\left(\mathrm{H}_{2} \mathrm{C}\right)-(\mathrm{C}=\mathrm{O})-$ of this same species, labeled $\mathrm{XIII}_{\mathrm{k}}$. These data suggest that in ECD experiments

(a) side-chain loss should not be competitive with $\mathrm{N}-\mathrm{C}_{\alpha}$ bond cleavage except for the tyrosine side chain (where the barrier to side-chain loss is lowered by delocalization of the nascent radical), and

(b) any side-chain cleavage should produce products in the $-(\mathrm{HC})=\mathrm{C}(\mathrm{OH})-$ isomer of species XIII because rearrangement to the keto isomer $\mathrm{XIII}_{\mathrm{k}}$ must overcome a large barrier.

It is interesting at this point to contrast and compare our findings on the carbon-radical- and nitrogen-radical-initiated 
backbone and side-chain cleavage energy profiles. Of course, the former arises in ECD, in which the initial step is the highly exothermic capture of the free electron, whereas the latter arises in EDD where there is no such highly exothermic initial step. By comparing Figures 1 and 7, we note that

(a) $\mathrm{C}_{\alpha}-\mathrm{C}$ bond cleavage is nearly thermoneutral and involves surmounting a rather small (ca. $7 \mathrm{kcal} \mathrm{mol}^{-1}$ ) barrier, while

(b) $\mathrm{N}-\mathrm{C}_{\alpha}$ bond cleavage is endothermic (by ca. $9 \mathrm{kcal} \mathrm{mol}^{-1}$ ) and involves a significantly higher barrier (ca. $17 \mathrm{kcal} \mathrm{mol}^{-1}$ ).

From Figures 3-6 and 8-11, we see that for both nitrogenand carbon-initiated side-chain cleavage, tyrosine is predicted to have the lowest energy requirement.

\section{Summary}

Making use of ab-initio electronic structure methods, we are able to predict that the nitrogen-centered radicals formed in EDD experiments are more likely to undergo $\mathrm{C}_{\alpha}-\mathrm{C}$ bond cleavage than side-chain loss. However, loss of a side chain such as tyrosine that can delocalize its radical electron may compete with $\mathrm{C}_{\alpha}-\mathrm{C}$ cleavage. In addition, our results allow us to understand why fragmentation of the nitrogen-centered radicals produces $\mathrm{a} \bullet / \mathrm{x}$ fragments rather than $\mathrm{a} / \mathrm{x} \bullet$ fragments. Formation of $\mathrm{a} \bullet / \mathrm{x}$ products is favored both thermodynamically, as earlier workers noted, ${ }^{3 a}$ and also kinetically. Finally, comparisons are made with the energetics for fragmenting (either by $\mathrm{N}-\mathrm{C}_{\alpha}$ cleavage or side-chain loss) carbon-centered radicals believed to be formed in ECD experiments, and comparisons between the cleavages arising from nitrogen and carbon radicals are made.

Acknowledgment. Support of the National Science Foundation through Grant CHE 0240387 is appreciated as is the support by the Polish State Committee for Scientific Research (KBN) under Grant BW/8000-5-0283-5. Significant computer time provided by the Center for High Performance Computing at the University of Utah is also gratefully acknowledged. Finally, we thank both referees for insightful comments that helped improve this paper.

\section{References and Notes}

(1) (a) Zubarev, R. A.; Kelleher, N. L.; McLafferty, F. W. J. Am. Chem. Soc. 1998, 120, 3265-3266. (b) Zubarev, R. A.; Kruger, N. A.; Fridriksson, E. K.; Lewis, M. A.; Horn, D. M.; Carpenter, B. K.; McLafferty, F. W. J. Am. Chem. Soc. 1999, 121, 2857-2862. (c) Zubarev, R. A.; Horn, D. M.; Fridriksson, E. K.; Kelleher, N. L.; Kruger, N. A.; Lewis, M. A.; Carpenter, B. K.; McLafferty, F. W. Anal. Chem. 2000, 72, 563-573. (d) Zubarev, R. A.; Haselmann, K. F.; Budnik, B.; Kjeldsen, F.; Jensen, F. Eur. J. Mass Spectrom. 2002, 8, 337. Much of the pioneering work aimed at understanding the mechanism(s) by which ECD operates has been reported in refs 1 and by the Turecek and Uggerud groups in, for example, the following refs 1(e),1(f): (e) Syrstad, E. A.; Turecek, F. J. Phys. Chem. A 2001, 105, 11144-11155. (f) Turecek, F.; Syrstad, E. A. J. Am. Chem. Soc. 2003, 125, 3353-3369. (g) Turecek, F.; Polasek, M.; Frank, A.; Sadilek, M. J. Am. Chem. Soc. 2000, 122, 2361-2370. (h) Syrstad, E. A.; Stephens, D. D.; Turecek, F. J. Phys. Chem. A 2003, 107, 115-126. (i) Turecek, F. J. Am. Chem. Soc. 2003, 125, 5954-5963. (j) Syrstad, E. A.; Truecek, F. Am. Soc. Mass Spec. 2004, 16, 208-224. (k) Uggerud, E. Int. J. Mass Spectrom. 2004, 234, 45-50. Our group has also contributed to analyzing mechanistic issues in ECD; see, for example, refs 1(1),1(m): (1) Anusiewicz, I.; Berdys-Kochanska, J.; Simons, J. The Electron Attachment Step in Electron Capture (ECD) and Electron-Transfer Dissociation (ETD). J. Phys. Chem., in press. (m) Anusiewicz, I.; Berdys-Kochanska, J.; Skurski, P.; Simons, J. Simulating Electron Transfer Attachment to a Positively Charged Model Peptide. J. Phys. Chem., in press. (n) Sawicka, A.; Berdys-Kochaska, J.; Skurski, P.; Simons, J. Int. J. Quantum Chem. 2005, 102, 838-846. (o) Sawicka, A.; Skurski, P.; Hudgins, R. R.; Simons, J. J. Phys. Chem. B 2003, 107, 13505-13511.

(2) Of course, a hydrogen atom can subsequently transfer from the $\mathrm{C}-\mathrm{OH}$ unit to the nitrogen atom generating the more stable $\mathrm{C}=\mathrm{O}-\mathrm{NH}_{2}$, although this rearrangement has a substantial barrier in the gas phase as we show later.

(3) (a) Kjeldsen, F.; Silivra, O. A.; Ivonin, I. A.; Haselmann, K. F.; Gorshkov, M.; Zubarev, R. A. Chem. Eur. J., in press. (b) Budnik, B. A.; Haselmann, K. F.; Zubarev, R. A. Chem. Phys. Lett. 2001, 342, 299-302. (c) Haselmann, K. F.; Budnik, B. A.; Kjeldsen, F.; Nielsen, M. L.; Olsen, J. V.; Zubarev, R. A. Eur. J. Mass Spectrom. 2002, 8, 117-121.

(4) Stephens, P. J.; Devlin, F. J.; Chabalowski, C. F.; Frisch, M. J. J. Phys. Chem. 1994, 98, 11623.

(5) McLean, A. D.; Chandler, G. S. J. Chem. Phys. 1980, 72, 5639.

(6) Krishnan, R.; Binkley, J. S.; Seeger, R.; Pople, J. A. J. Chem. Phys. 1980, 72,650 .

(7) Pople, J. A.; Head-Gordon, M.; Raghavachari J. Chem. Phys. 1987, 87, 5968.

(8) Frisch, M. J.; Trucks, G. W.; Schlegel, H. B.; Scuseria, G. E.; Robb, M. A.; Cheeseman, J. R.; Montgomery, J. A., Jr.; Vreven, T.; Kudin, K. N.; Burant, J. C.; Millam, J. M.; Iyengar, S. S.; Tomasi, J.; Barone, V.; Mennucci, B.; Cossi, M.; Scalmani, G.; Rega, N.; Petersson, G. A.; Nakatsuji, H.; Hada, M.; Ehara, M.; Toyota, K.; Fukuda, R.; Hasegawa, J.; Ishida, M.; Nakajima, T.; Honda, Y.; Kitao, O.; Nakai, H.; Klene, M.; Li, X.; Knox, J. E.; Hratchian, H. P.; Cross, J. B.; Adamo, C.; Jaramillo, J.; Gomperts, R.; Stratmann, R. E.; Yazyev, O.; Austin, A. J.; Cammi, R.; Pomelli, C.; Ochterski, J. W.; Ayala, P. Y.; Morokuma, K.; Voth, G. A.; Salvador, P.; Dannenberg, J. J.; Zakrzewski, V. G.; Dapprich, S.; Daniels, A. D.; Strain, M. C.; Farkas, O.; Malick, D. K.; Rabuck, A. D.; Raghavachari, K.; Foresman, J. B.; Ortiz, J. V.; Cui, Q.; Baboul, A. G.; Clifford, S.; Cioslowski, J.; Stefanov, B. B.; Liu, G.; Liashenko, A.; Piskorz, P.; Komaromi, I.; Martin, R. L.; Fox, D. J.; Keith, T.; Al-Laham, M. A.; Peng, C. Y.; Nanayakkara, A.; Challacombe, M.; Gill, P. M. W.; Johnson, B.; Chen, W.; Wong, M. W.; Gonzalez, C.; Pople, J. A. Gaussian 03, Revision A.1; Gaussian, Inc.: Pittsburgh, PA, 2003.

(9) From the DFT-level data of Figure 3 it would appear that valine side-chain loss could also be competitive. However, as we noted earlier, substantial spin contamination was encountered in the valine case. The spinprojected PMP2 data also shown in Figure 3 would suggest (when compared with PMP2 data for the other side chains shown in Figures 4-6) that the energy profile for valine is likely more similar to those obtained for arginine and glutamic acid than for that for tyrosine. Thus, discounting the spincontaminated data, we believe the statement that only side-chain loss of tyrosine, with its radical delocalization ability, can compete with backbone cleavage. 